\title{
Seduepb
}

\section{Tempos sociais acelerados, patrimônio cultural em risco}

\author{
José Clerton de Oliveira Martins
}

\section{SciELO Books / SciELO Livros / SciELO Libros}

MARTINS, JCO. Tempos sociais acelerados, patrimônio cultural em risco. In BRASILEIRO, MDS., MEDINA, JCC., and CORIOLANO, LN., orgs. Turismo, cultura e desenvolvimento [online]. Campina Grande: EDUEPB, 2012. pp. 169-193. ISBN 978-85-7879-194-0. Available from SciELO Books < http://books.scielo.org>.

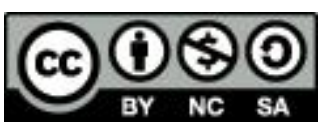

All the contents of this work, except where otherwise noted, is licensed under a Creative Commons Attribution-Non Commercial-ShareAlike 3.0 Unported.

Todo o conteúdo deste trabalho, exceto quando houver ressalva, é publicado sob a licença Creative Commons Atribuição Uso Não Comercial - Partilha nos Mesmos Termos 3.0 Não adaptada.

Todo el contenido de esta obra, excepto donde se indique lo contrario, está bajo licencia de la licencia Creative Commons Reconocimento-NoComercial-CompartirIgual 3.0 Unported. 


\title{
Tempos sociais acelerados, patrimônio cultural em risco
}

\author{
José Clerton de Oliveira Martins
}

\section{Introdução}

O foco central deste capítulo é refletir sobre as temporalidades socialmente instituídas e suas consequências sobre o patrimônio cultural e sobre nós mesmos. A partir dos qualificativos atribuídos por Lipovetsky (hiperconsumista), Bauman (líquida) e Beriain (apressada), entendemos que o ritmo social acelerado que elegemos afeta o valor que atribuímos ao tempo da elaboração de identidades e apropriação de lugares. $\mathrm{O}$ valor centralizado no tempo produtivo pode acarretar danos físicos e mentais aos sujeitos da contemporaneidade, assim como também ao patrimônio cultural dos lugares, uma vez que não há tempo para a vinculação de pessoas aos lugares. 
A relação entre patrimônio cultural e o sujeito que o elabora, leva em conta as identidades de lugar elaboradas ao longo do tempo que o sujeito se elaborou como vinculado a um espaço, que tomou como seu. Nesta perspectiva, o tempo livre é um âmbito importante para esta possibilidade. No entanto, o que observamos é que o tempo livre está cada vez mais comprometido com o exterior, regido pelo tempo produtivo, tornando um apêndice deste.

No decorrer da História, o tempo, enquanto um fenômeno sócio-histórico, constituído de elementos filosóficos, religiosos e culturais, incorporou diversos sentidos. $\mathrm{Na}$ antiguidade, por exemplo, o espaço temporal era percebido enquanto uma rede cíclica ligada aos ritmos naturais. Essa concepção prevaleceu no contexto Ocidental até meados do século VII d.C., época na qual as estruturas medievais começavam a se fortalecer (ELIAS, 1998).

Em um dado momento da História Ocidental, determinados fatores e condicionantes - de ordem econômica, social e cultural, transformaram o conceito de tempo em algo a parte e linear, isto é, em uma trajetória única que partiria do passado, cruzaria a nossa existência no presente e prolongar-se-ia rumo ao infinito. Dessa forma, a noção de tempo, enquanto algo despreocupante, desaparece, dando lugar a uma nova representação pautada na medição temporal.

Neste contexto, o relógio deixou de ser um objeto de luxo para ser um instrumento indispensável da vida diária. Uma importante base material da nova ideologia da vida, do trabalho, da produção e do progresso. Assim, o relógio se converteu em um ponto de apoio de uma nova temporalidade, representando uma consciência e concepção do tempo 
radicalmente diferente no transcurso cotidiano do homem (GÓMEZ, 1992, p. 86).

Diante desses fatos, é observado o aperfeiçoamento do poder coercitivo que o tempo cronometrado adquire frente aos indivíduos, o qual passa a desempenhar um papel controlador e regulador da vida humana, destacando que o poder "autorregulador" que este tempo possui sobre os indivíduos não é de caráter biológico, natural, ou metafísico, mas social, resultante da assimilação de inúmeros valores ideológicos (MARTINS, 2000).

Por exemplo, sabe-se que quando nos dias laborais, a maioria da população deve acordar cedo, tomar o transporte e chegar ao trabalho, também se sabe que durante o final de semana, pode-se dormir um pouco mais, pois não há atividade laboral. Estes comportamentos passam a ser incorporados (interiorizados) pelas formas estruturais desse tempo cronometrado, tornando-se uma rede de significados cada vez mais complexa, à medida que as formas de relações sociais vão sendo alteradas.

As informações e a praticidade, com o advento da tecnificação, permitiram aos homens realizar suas atividades cada vez mais rápido. No entanto, essa tecnologização que aparentemente facilitaria nossas vidas, na verdade nos orienta a adentrarmos em mais atividades, conduzindo-nos a preencher, ainda mais, todos os espaços diários. Esse processo, na atualidade, transparece-nos uma percepção de "aceleração do tempo", perante a realização de nossas atividades.

A sociedade apressada remete-se aos grupos ou comunidades que devido aos seus compromissos laborais, sociais e familiares, geram uma escassez temporal cada vez mais acentuada 
durante o seu tempo livre. Diante deste processo, o desequilíbrio temporal acaba por acarretar inúmeras patologias para o sujeito, como por exemplo, o tédio e o estresse.

Munné (1980), em suas colocações acerca desta temática e ao tomar como referencial a questão da autonomia, buscou empreender uma reflexão sobre a relação entre liberdade e condicionamento, tendo em vista que estes dois elementos, na maioria das vezes, são percebidos em oposição, sendo que, na realidade, coexistem mutuamente, isto é, “(...) não existe a liberdade sem o condicionamento, nem o condicionamento sem liberdade" (p. 69).

O referido autor entra em uma discussão acerca dos condicionantes: hetero e autocondicionado. O primeiro é um tipo de condicionamento externo, imposto e de fácil naturalização, por parte dos indivíduos. O segundo é condizente a um reconhecimento, por parte dos indivíduos, dos mecanismos sociais heterocondicionantes, para, então, poderem se autocondicionar.

O uso da autonomia está sempre sujeito a possibilidades, pois todas as atividades ocupadas no tempo social são resultantes de um heterocondicionamento ou autocondicionamento. Para tanto, diante deste pressuposto, outra questão emerge: Como diferenciar o tempo livre dos outros tempos sociais, seguindo essa lógica do condicionamento?

Para melhor esclarecimento, Munné (1980) propôs categorizar o tempo social em quatro tipos fundamentais: o tempo psicobiológico, o tempo socioeconômico, o tempo sociocultural e, por fim, o tempo livre. 
Em linhas gerais, o autor coloca sua compreensão sobre sua categorização dos referidos tempos sociais: Tempo psicobiológico seria o tempo ocupado por nossas necessidades psíquicas e biológicas, as condições endógenas, de cada indivíduo; Tempo socioeconômico seria aquele tempo ocupado pelas condutas derivadas das necessidades econômicas, sendo esta uma categoria social fortemente heterocondicionada, haja vista que, o autocondicionamento se manifesta em pequenas e isoladas situações ("escolha do trabalho", "tarefas de casa", etc.); Tempo sociocultural seria aquele dedicado às relações interpessoais (visita à casa de um amigo; brincar com os filhos, compromissos de ordem social diversa, etc).

Neste tempo, observa-se que o entrelaçamento entre os condicionantes hetero e auto encontram-se intimamente ligados e por fim o Tempo livre que seria aquele no qual deveria estar implicado um máximo autocondicionamento e um mínimo heterocondicionamento, ou seja, onde a disponibilidade pessoal seria superior às imposições do meio ou em outras palavras, é quando a necessidade de liberdade responsável se sobressai em relação aos demais imperativos.

Diante desses fatos, observa-se que o tempo voltado para atividades, experiências, ou estados onde a percepção de autonomia no condicionamento temporal abre espaço para o homem conhecer melhor a si e ao contexto no qual se encontra inserido, possibilitando a ele mesmo, ampliar o seu tempo e aproveitá-lo melhor, favorecendo dessa forma, a vivência de experiências atreladas ao desenvolvimento, satisfação e realização. Diante do exposto, expressamos a seguir impressões sobre características de nossa sociedade. 


\section{Qualificativos da sociedade contemporânea}

Ao pensar nos estilos que predominam em nossa sociedade atual, três observadores atentos nos oferecem alguns qualificativos que pela penetração que obtiveram a partir de seus trabalhos, levam-nos a convocá-los para ilustrar os estilos de vida predominantes. Os nomes são: Lipovetsky, Bauman e Josexto Beriain. Os qualificativos são respectivamente: hiperconsumista, líquida e apressada.

Ao falar do homem desse tempo, Lipovetsky comenta que os indivíduos desse momento são ao mesmo tempo mais informados e mais desestruturados, mais adultos e mais instáveis, menos ideológicos e mais tributários da moda e do consumo do supérfluo, mais abertos e ao mesmo tempo mais aprisionados às imagens de êxito pessoal via moda, usos de tecnologias de ponta e consumo efêmero (LIPOVETSKY, 2007).

Segundo ele, o consumismo representa uma forma degenerativa de se vincular aos objetos e ao mundo da interioridade, pois para o sujeito desse tempo é mais fácil lançar-se no fluxo frenético da aceleração e da intensidade regida pelo consumo, do que pensar sobre sua condição de ser, porque assim se daria conta do quão esvaída de sentidos e significados verdadeiros encontra-se a sua existência.

Nahipermodernidade, termo denominado por Lipovetsky para cunhar a sociedade atual, o homem torna-se vítima de si mesmo, aprisionado no tempo do trabalho produtivo que fomenta o consumo, reproduzindo um cotidiano em que tenta de todas as formas furtar-se das possibilidades entediantes da vida. Assim, a sociedade cria e divulga formas efêmeras de entretenimentos visando à diminuição do sentimento mais 
presente na atualidade - o tédio. Neste contexto, a indústria da diversão e dos lazeres fomentam experiências inventadas em formas de divertimentos que ilusoriamente encobrem esse sentimento e assim conservam os sujeitos sob controle.

\section{A liquidez contemporânea}

Para Bauman (1998), uma das características mais marcantes desta nossa sociedade é a liquidez. Assim, o tempo desta sociedade é tomado como um tempo líquido, o amor como amor líquido dado a efemeridade como tudo se elabora e se desintegra, tal como os materiais elaborados para logo se transformarem em lixo. Nesta sociedade, não existe nada que possa durar por muito tempo. Assim tudo tem curto prazo de vitalidade, como as impressoras que possuem prazo para parar de funcionar depois de número " $\mathrm{x}$ " de impressóes, ou das baterias criadas para serem usadas, perder a validade e serem substituidas por novas. $\mathrm{O}$ novo fascina. $\mathrm{O}$ último modelo seduz por sua imagem de inovação e dinamismo.

Nesse tempo, tudo se torna obsoleto muito rápido: pensamentos, ideias, sentimentos, relações. A dinâmica é rápida e fluída não existindo mais o sentido do vínculo e do tempo da apuração dos valores que antes sustentavam as tradições, as relações, as crenças, etc. Tudo se esvai.

No contexto dessa sociedade que se projeta a partir dos apelos midiatizados pelo consumo, Beriain (2008) olha para ela e observa que o curso da vida passa a ser regido pela intensificação da aceleração advinda da lógica capitalista, alinhada aos valores que estimulam o consumo que por sua vez, propicia uma nova configuração das relações sociais. 


\section{A pressa que se instala como demarcadora do ritmo social}

$\mathrm{Na}$ sociedade do consumo, busca-se obter mais prazer o mais rápido possível, privilegiando a quantidade em detrimento da qualidade das relações, tudo isso para que se possa obter êxito e reconhecimento no "aqui e no agora", e para isso não há tempo para elaboração, deve ser tudo instantâneo. Já! Nesta sociedade, o futuro é o agora, não se pode esperar para ser feliz, compra-se a felicidade, a realização e o prazer.

$\mathrm{Na}$ aceleração pensada por Beriain (2008), as distâncias e os espaços e tempos se suprimem frente o desejo de viver tudo que for possível de forma intensa, na busca insensata de prazereres imediatos, satisfação de necessidades de toda ordem e realização no aqui e agora, pois o futuro pode ser atencipado e todos podemos ser felizes não no futuro, mas no presente que o antecipa. Nesta lógica da pressa, se minha felicidade depende da posse de um objeto, posso antecipar o futuro feliz e comprar meu símbolo de felicidade em dez vezes no cartão.

Esse pensamento se torma comum a partir das conquistas proporcionadas pela rapidez nas formas de pensar, de agir, de produzir e consumir, via novas tecnologias. Nesse contexto, ocorre um novo delineamento das necessidades e demandas do sujeito hipermoderno que acenam para um ideal de felicidade que traz em si a promessa de ser concretizada mediante ao que se consome. Na sociedade do hiperconsumo, o que importa é o que se tem, no sentido de possuir via objeto/coisa.

No curso da aceleração, o tempo do aqui e agora é transformado no tempo de todos os lugares, já que os limites e as barreiras são desfeitas pelo alcance da velocidade dos recursos. Assim, é possível ao homem estar aqui e agora em todos os lugares. 
Nessa perspectiva, o espaço e o tempo são tomados por um vazio no qual o sujeito não consegue atribuir sentido, passando a dar-se conta de que o centro não está em nenhum lugar e ao mesmo tempo em todos os lugares (BERIAIN, 2008). Com efeito, passa-se a ter um olhar turvo ao tentar reconhecer-se neste turbilhão de acontecimentos e de múltiplas demandas a si direcionadas.

O autor ainda aponta que como consequência desta dinâmica social, há o aumento exponencial da vida nervosa, que favorece a ansiedade e diversas manifestações psicossomáticas em decorrência da luta desesperada desse sujeito tomado de seu tempo, para se manter inserido num contexto cada vez mais excludente e em sintonia com os valores dominantes.

Esse sujeito passa então a exigir de si mesmo mais rapidez de pensamento e mais agilidade em suas ações, muitas vezes tomando para si o que está fora de suas possibilidades, não se permitindo o tempo necessário para "tornar-se capaz", pois tempo não há, gerando frustração, violência, estresse, culpa e outras sensações negativas as relações, tão necessárias à existência em equilíbrio.

\section{Tempo livre da sociedade líquida, apressada e consumista.}

Neste contexto, uma questão nos convoca. Como se organiza o tempo livre de uma sociedade centrada no tempo produtivo e no consumo decorrente desta produção? Na realidade, o que é considerado tempo livre numa sociedade que se organiza sob tais centralidades? No Brasil, três termos são usados no cotidiano de forma corrente como sinônimos. No 
entanto, sabe-se que tais termos possuem peculiaridades em seus significados, quando nos aproximamos de suas nuances. Os termos são: lazer, ócio e tempo-livre.

O termo lazer, desde a década de 1960 do século XX, é utilizado de forma crescente, sendo associado a palavras como entretenimento, turismo, divertimento e recreação; porém o sentido do lazer é tão polêmico quanto a origem e o sentido do termo ócio. Observa-se que a palavra lazer, no Brasil, resguarda seu conceito relacionado à sociologia do lazer de Dumazedier $(1973 ; 1979)$, que levou à popularização da sua teoria dos três "D's". De acordo com o referido autor, o lazer é exercido à margem das obrigações sociais e encontra-se submetido a um lugar de destaque, com funções de descanso, desenvolvimento da personalidade e diversão.

Desta forma, lazer adentra o pensamento brasileiro a partir do pensamento da sociologia e percebe-se, observando a literatura existente, a influência de Dumazedier na elaboração deste conceito. Decorrente disso, lazer passou a representar,

Conjunto de ocupações às quais os indivíduos podem entregar-se de livre vontade, seja para repousar, seja para divertir-se, recrear-se e entreter-se ou, ainda para desenvolver sua formação ou informação desinteressada, sua participação social voluntária ou sua livre capacidade criadora, após livrar-se ou desembaraçar-se das obrigaçóes profissionais, familiares e sociais (DUMAZEDIER, 1979, p.34). 
A palavra ócio, por outro lado, resguarda valores negativos apregoados pela influência religiosa cristã, pela própria história da industrialização e modernização brasileira, ao longo da qual se pode observar o surgimento de uma nova ordem entre empresários e empregados, operários e patrões; e a necessidade de controle social no tempo fora do trabalho para garantir a ordem numa sociedade elitista, herdeira de valores colonialistas e escravagistas.

Ócio representa uma categoria muito antiga que convoca muitas possibilidades, mas após a Revolução Industrial, com o surgimento do chamado tempo livre, fruto das conquistas da classe operária frente à exploração do capital, é que o fenômeno foi evidenciado, ocorrendo a nítida separação entre tempo-espaço de trabalho (tempo produtivo, tempo central e mais importante do indivíduo digno) e ócio (atividades contrárias ao trabalho, tempo secundário, improdutivo) confundindo-se com o lazer, enquanto que o tempo livre passou a ser compreendido como aquele destinado às atividades de lazer ou ócio, voltadas à reposição física e mental do sujeito trabalhador.

Estudos atuais evidenciam que os termos em questão; ócio, tempo livre e lazer, possuem possibilidades diversas pelo contexto de liberdade que invocam. No caso, tempo livre e lazer se apresentam na dinâmica social brasileira carregado dos valores do sistema econômico dominante, relacionando-se diretamente com tempo de reposição de energia para o trabalho.

O ócio envolve um sentido de utopia por orientar a uma liberdade, supostamente longe de ser alcançada, haja vista a própria dinâmica socioeconômica preponderante. No 
entanto, ao convocarmos as dimensões psicológicas e subjetivas, retoma-se a possibilidade do ócio autotélico, inclusive em tempos onde o sujeito é sacado de si a partir dos apelos consumistas e até mesmo pela educação que orienta na mesma direção.

Novos investigadores surgem, no Brasil, aportando abordagens críticas aos estudos do lazer, explicitando a necessidade de visualização do fenômeno como fruto de um processo econômico social específico. Assim, o lazer como se compreende, na atualidade, surge como algo que transcende a autonomia subjetiva. Chega-nos mais como reivindicações sociais por parte da classe trabalhadora na necessidade de mais tempo liberado de obrigações, este muito mais representado como um tempo de reposição de energia para o trabalho produtivo.

Nesta abordagem, nota-se a nítida separação entre tempo de trabalho e tempo de lazer, onde primeiro está o trabalho como tempo central e ao redor dele e em sua dependência, organizam-se todos os demais contextos. Em segundo, está o lazer, apresentando-se, em primeiro momento, como representação de descanso, diversão e desenvolvimento.

É claro que nestas possibilidades tudo está pensado em relação e conforme os ditames da centralidade para a qual tudo se volta, ou seja, diversão sob controle, fabricada na forma de entretenimentos que alimentam a lógica consumista e desenvolvimento representado muito mais como lugar da informação, formação, etc, voltado para a mesma lógica. Note-se nesta possibilidade a visão dicotômica dos tempos, num momento este, noutro aquele. 
Devido ao processo de industrialização e modernização, as relações sociais sofreram profundas transformações. Trabalho e lazer assumem neste momento uma nova ordem através de intenso controle social via novos domínios, no intuito de garantir a lógica do capital, atualizada ao modelo "cool" contemporâneo, que se interpreta a partir do sujeito que a tudo se molda rapidamente, assumindo-se como atualizado, antenado, conectado, "no último".

\section{Transformações nas compreensões do termo lazer}

Conforme já citado, o termo lazer toma vulto, no Brasil, a partir das ideias do sociólogo francês Joffre Dumazedier. O autor enfatiza os valores do lazer enquanto relevantes no processo de desenvolvimento do indivíduo que vivencia um cotidiano da sociedade centrada no trabalho. Em sua concepção, o lazer era exercido à margem das obrigações sociais em um tempo distante das obrigaçóes.

Com destacada produção, Nélson Marcelino aponta o lazer como uma atividade desinteressada, sem fins lucrativos ou utilitários, sociabilizante e liberatória. Contesta o lazer enquanto instrumento de acomodação, de dominação, alienação, minimizando o conflito social, oriundo de reflexões mais aprofundadas como no significado da expressão "pão e circo para o povo". E mais ainda, denuncia a dimensão comumente apresentada de lazer-mercadoria como uma rentável fonte de bens e serviços a serem consumidos (MARCELINO, 1983).

Ressaltando a manifestação do lazer sob a forma de mercadoria representada por experiências em sintonia com a 
lógica hegemônica do consumismo massificado, Mascarenhas (2005) conceitua o lazer de nosso tempo como uma atividade de mercado e o denominou de mercolazer:

(...) mas o fato é que tendencial e predominantemente o que ele [Lazer] constitui mesmo é uma mercadoria cada vez mais esvaziada de qualquer conteúdo verdadeiramente educativo, objeto, coisa, produto ou serviço em sintonia com a lógica hegemônica de desenvolvimento econômico, emprestando aparências e sensações que, involucralmente, incitam o frenesi consumista que embala o capitalismo avançado. $\mathrm{O}$ que estamos querendo dizer é que num movimento como nunca antes se viu o lazer sucumbe de modo direto e irrestrito à venalidade universal. (...) Isto, pois o mercolazer tanto é reflexo e expressão dos divertimentos em tempos de acumulação flexível, como também é componente decisivo que opera para a sustentação e o sucesso deste modelo de acumulação. (p.140/141)

Os elementos: humanização, desenvolvimento, expressão, poder criativo, livre escolha, dentre outros, suscitam um convite para uma discussão mais aprofundada dos atos e relações, riscos e possibilidades, bem como das formas e como utilizamos nosso tempo livre para o lazer. Utilizamos de maneira satisfatória? Adequamos bem aos nossos desejos?

O termo lazer atualmente é utilizado de forma crescente, associado a palavras como diversão, entretenimento, recreação e turismo, demonstrando que uma nova era de mercantilização 
dos modos de vida às práticas de consumo exprima uma nova relação com as coisas, com os outros e consigo.

A dinâmica de expansão das necessidades se prolonga, mas carregada de novos significados coletivos e individuais. A era do consumo de massa mudou de fisionomia e chega-se a uma nova fase de sua história secular. As indústrias e os serviços empregam lógicas de opção, estratégias de personalização dos produtos e dos preços, políticas de segmentação, mas todas essas mudanças não fazem mais que ampliar a mercantilização dos modos de vida, alimentar um pouco mais o frenesi das necessidades e avançar na lógica do "sempre mais, sempre novo". A nova sociedade funciona mais por hiperconsumo, que por "des-consumo" (LIPOVETSKY, 2007).

Do contexto dessa sociedade atual, surge um homem eufórico por vivências prazerosas espetaculares submersas em valores extremos como trabalho e consumo numa ótica globalizada de liberalismo econômico. Nessa busca pelo prazer hedonista, há uma intensificação pela aceleração social das relações provocadas pela rapidez da evolução das máquinas, computadores, microeletrônica, etc.

Embora o tempo livre, originalmente resguarde um caráter subjetivo, ou seja, de escolha individual, o que se percebe é que hoje a lógica do consumo, onde tudo é mercantilizado, acaba interferindo e se fazendo presente nessas escolhas. Ao utilizar o tempo livre para ir ao cinema, ir ao shopping, viajar a turismo, constata-se que tais atividades implicam em relações de consumo e estas são direcionadas pelas categorias que determinam o segmento a que cada lazer se volta, na perspectiva mercadológica. Em assim sendo, liberdade e autonomia não podem ser creditadas a esta ação. 
Dessa forma, o lazer, por estar tão relacionado ao consumo, acaba contribuindo para a impossibilidade de construção de uma subjetividade e de significação da atividade/ experiência de forma autônoma. O que se percebe, então, é que o lazer no tempo livre da sociedade hipermoderna não está focado no bem-estar dos sujeitos, nem tão pouco no seu desenvolvimento.

O termo "lazer" representou, em algum tempo, uma escolha pessoal daquilo que decidimos realizar em nosso tempo livre, porém, na realidade, essa escolha, supostamente autônoma, acabou sofrendo influências exteriores. Chegou-se a propagar que estavam reservadas ao lazer as atividades normalmente gratuitas, prazerosas, desenvolvidas no tempo livre.

$\mathrm{Na}$ atual sociedade urbanizada das grandes metrópoles, percebe-se que o lazer, de uma forma ou de outra, é conduzido pelo consumo através de entretenimentos fabricados, kits elaborados e decididos por especialistas em consumo, para um segmento de sujeitos de acordo com seu poder de consumo, desconsiderando as subjetividades implicadas.

Assim, o lazer sucumbiu ao consumismo, ou seja, o que o indivíduo produz com sua força de trabalho, gasta com compras de serviços e objetos no seu tempo de não trabalho, ludibriado pela sensação de que está em desfrute do seu merecido ócio e de plena liberdade de escolha.

Percebe-se, desta maneira, um desperdício da vida com a realização de atividades e práticas que, crescentemente, incentivam o consumo como força propulsora cíclica que aprisiona o sujeito na manutenção do sistema produtivo e, ao mesmo tempo, o mantém como agente de tal dinâmica diante dos efeitos nefastos que incidem sobre si mesmo. 
No âmbito social, aquele que permanece coerente com essa lógica possui reconhecimento social, porém, muitas vezes, não reconhece a si mesmo, uma vez distanciado dos seus principais referenciais. Já aquele que não mantém coerência desespera-se na possibilidade de vir a ter, experimentando também inquietação e mal-estar, pela condição real ou potencial de exclusão social.

No cenário que enfatiza as promessas de satisfação, ecoa paradoxalmente a expressão de sofrimento psíquico, manifesto através de inúmeras doenças psicossomáticas que acometem o sujeito, como indicadoras de que o estilo de vida atual não mais é possível de ser sustentado.

\section{O contramovimento possibilitado pelo ócio}

No tempo de uma sociedade sem tempo, tudo se torna obsoleto muito rápido: pensamentos, ideias, sentimento, relações. A dinâmica é rápida e fluida não existindo mais o sentido do vínculo e do tempo da apuração dos valores que antes sustentavam as tradições, as relações, as crenças, etc. Tudo se esvai.

Nesse contexto, somos incitados a pensar novas possibilidades de subjetivação do tempo disponível, a partir das quais o sujeito poderia vivenciar esse tempo com mais qualidade, por meio de uma (re)significação da sua forma de ser e estar no mundo. Assim, pensamos numa retomada dos componentes básicos do tempo livre que, em um momento, resguardou certo sentido "autotélico". 
Neste sentido, o pensamento sobre ócio retomado no Brasil, nos anos 1980, sinaliza um contramovimento em relação aos mecanismos econômicos centrados em estilos de vida que focalizam apenas os fins lucrativos.

Salis (2004) aponta para pensarmos sobre a psicagogia, que seria $o$ caminho para o homem construir-se a partir do reencontro consigo mesmo, proporcionado pelo constante olhar para si, para seus valores mais inerentes, guiados por seus próprios talentos.

De acordo com o referido autor, ao perdermos o bem mais precioso que possuímos - o tempo - no emprego de atividades ou afazeres que asseguram um status de forma não coerente com o que confere significado subjetivo de realização, o sujeito experimenta, muitas vezes, o vazio ou a escassez de sentidos em suas experiências, convocando para si desequilíbrios de diversas ordens.

Nesse cenário, apresenta-se o ócio em sua perspectiva autotélica (CUENCA, 2000) como possibilidade de experiência subjetiva, que expressa um contramovimento aos valores dominantes, capaz de conduzir o sujeito a uma (re)significação do seu tempo livre, dotando de mais valor a sua condição de se estar no mundo, pela consciência de que a experiência de vivenciar um tempo livre com significado é realmente, transformadora. 


\section{Patrimônio Cultural na sociedade de sujeitos sem tempo}

Ao pensar numa sociedade que resquarda as características postas pelos autores citados, somos convocados a algumas inferências sobre os significados dos espaços e lugares elaborados por seus sujeitos. Assim, em relação aos seus atrativos: qual o significado do Patrimônio Cultural destas sociedades? Como pensar uma educação patrimonial para sociedades apressadas, consumistas e líquidas?

Martins (2006), de acordo com Aguirre (1997), sugere que num sentido bem amplo, a palavra patrimônio equivale à Cultura, na perspectiva que o termo assume uma função globalizante, assinalando tratar-se do principal testemunho da contribuição histórica para as civilizações universais, da capacidade criativa contemporânea, não podendo ser resumido apenas a um conjunto de bens dignos de conservação, por razões de arte e de cultura.

O conceito de patrimônio cultural, então, envolve em grande escala o feito humano atrelado a um contexto. Uma vez que todo o espaço ocupado pelo Homem pressupóe uma atuação que significa a busca de sobrevivência, felicidade e bem-estar. O espaço geográfico natural está impresso pelo resultado da ação do homem, levando-nos a inferir que tudo que representa sua pegada, seja no nível material, ou simbólico, representa uma interferência humana, que significa cultura, na lógica de Aguirre, por isso mesmo é patrimônio cultural (MARTINS, 2006).

O patrimônio, desta forma percebido, não é algo sem importância, fruto de convenções sociais. É dinâmico, 
proporciona aprofundamento nos contextos sociais, históricos, econômicos etc, convocando muita atenção e cuidado, pois trata-se das "nossas coisas" elaboradas ao longo do tempo que existimos enquanto "identidades culturais" que convocamos.

Desta forma, compreender o direito à memória como dimensão da cidadania implica reformular as relações entre o sujeito e suas produções culturais. Cabe às instituições, desde as mais básicas, família, escola, comunidade, grupo, etc, em seus mais diversos níveis incorporar o valor de nossas tradições, valores e patrimônio, possibilitando promover a importância dos museus, dos sítios, das festas, do artesanato, da regionalidade, para que se possa alcançar, a dimensão da importância desses itens do patrimônio para nós mesmos, para o povo que somos, para os sujeitos que nos elaboramos a cada momento.

Ao pensarmos assim, somos levados a elaboraçóes sobre o que vem a tratar a educação para o uso do tempo livre rumo a valorização da cultura local que, por sua vez, se lança numa perspectiva também de educação patrimonial.

Horta et al (1999) nos apontam que a educação patrimonial trata-se de um processo permanente e sistemático de trabalho educacional centrado no Patrimônio Cultural como fonte primária de conhecimento e enriquecimento individual e coletivo.

Na mesma perspectiva da proposta de uma educação para o ócio, trata-se de um âmbito para o reencontro do indivíduo consigo e com suas produções mais intrínsecas, influenciando-o em sua autoestima através da valorização, apropriação e reconhecimento de sua cultura e identidades, ao perceber 
seu entorno e a si mesmo em seu contexto cultural como um todo, transformando-se em principal agente de preservação.

O conhecimento crítico e a apropriação consciente das comunidades sobre seu patrimônio cultural e o valor desse conhecimento para os diversos âmbitos são fatores indispensáveis para o processo de preservação sustentável desses bens, assim como para o fortalecimento dos pertencimentos, identidades e cidadania.

Nesta possibilidade, a educação patrimonial assim como a educação para o ócio tornam-se processos constantes de ensino/aprendizagem rumo a um sujeito conhecedor do que é em tempos de desvinculações, solidões e desestruturações. Convocando a consciência de um ser ao mesmo tempo universal e responsável proprietário, apropriado de um lugar no mundo que é a sua cara, onde este se sente projetado, integrado e compreendido.

Em assim sendo, educação patrimonial vai para além de informação e conhecimento. Trata-se de um processo de consciência de ser cidadão, de ser responsável pelo todo elaborado de um mundo ou parte dele. Representa uma ação não apenas para preservação, para a defesa da memória da história, do respeito e das referências tão necessárias para ser o que somos: pessoas de um lugar, com referências, pertencimentos bem peculiares que por sermos da raça humana, somos ao mesmo momento, locais e universais. 


\section{Reflexões finais}

Para finalizar, cremos que em tempos de liquidez, vazio, tédio e superconsumo, existe um potencial em nós que, quando acessado, pode amenizar os efeitos de nossa projeção nas coisas compradas: a educação patrimonial pode nos transportar para dentro de nós mesmos, elaborando um rebuscamento interior onde seria possível um reencontro e quem sabe um reconhecimento de nossas coisas mais essenciais, que são nossos pertencimentos verdadeiros, elaborados a partir de nossas referências, deixando a sensação de que em meio às nossas coisas e nossos valores mais essencias, podemos, quem sabe, sentir-nos sempre acolhidos, revelando algo que evita-se falar nestes tempos esvaziados de sentidos: os vínculos que sugerem afetos, que sugerem pertencimentos, vínculos. Estes valores emocionais reverberam no patrimônio cultural, fazendo-o um elemento de reconhecimento de si e, consequentemente, é protegido, experimentado e, sobretudo, preservado. Apenas pelo fato de ser um reflexo do homem que teve tempo de criá-lo e fazê-lo uma parte de si.

\section{Referências}

AGUIRRE, A. Cultura e Identidad Cultural. Barcelona: Ed. Bardenas. 1997.

BAUMAN, Z. O Mal-Estar da Pós-Modernidade. Rio de Janeiro: Ed. Zahar, 1998.

, Comunidade: A busca por segurança no mundo

atual. Rio de Janeiro: Jorge Zahar. 2003. 
, Modernidade Líquida. Buenos Aires: FCE.

2002.

BERIAIN, J. Aceleración y tirania del presente. La metamorfosis en las estructuras temporales de La modernidad. Barcelona-España: Anthropos Editorial, 2008.

CUENCA, C. M. Ocio humanista: dimensiones y manifestaciones actuales del ocio. Bilbao, España: Universidad de Deusto. 2000.

CSIKSZENTMIHALYI, M. Fluir: Una psicología de la felicidad. Barcelona. España: Cairos 1997.

DUMAZEDIER, J.: Lazer e cultura popular. São Paulo: Editora Perspectiva, 1973.

: Sociologia empírica do Lazer. São

Paulo: Editora perspectiva, 1979.

GOMES, C. L. (org.): Dicionário Crítico do lazer. Belo Horizonte: Autêntica, 2004.

KLEIBER, D. A. Leisure experience and human development: A dialectical interpretation. Nueva York, NY, EE.UU.: Basic Books, 1999.

HORTA, M. de L. P., GRUNBERG, E., MONTEIRO, A. Q.: Guia Básico de Educação Patrimonial. Brasília: Instituto do Patrimônio Histórico e Artístico Nacional, Museu Imperial. 1999. 
LIPOVETSKY, G. Tempos hipermodernos. São Paulo:

Barcarolla, 2004.

MARTINS, C. Patrimônio Cultural da memória ao sentido do lugar. São Paulo: Ed. Roca. 2006.

MASCARENHAS, F. Entre o ócio e o negócio: teses acerca da anatomia do lazer. Tese (Doutorado) - Faculdade de Educação Física, Universidade Estadual de Campinas/ UNICAMP. Campinas, SP: [s.n], 2005.

MARCELINO, N. C.: Lazer e Humanização. São Paulo: Papirus, 1983.

SP: Ed. Alínea, 2007. : (org.) Lazer e cultura. Campinas,

MATURANA, H. R.. Emoções e linguagem na educação e na política. Belo Horizonte: Ed. UFMG, 1998.

MUNNÈ, F. La psicosociologia del tiempo libre. Cidade do Mexico.DF: Ed. Trilla. 1980.

SALIS, V. D. Ócio Criador, Trabalho e Saúde. São Paulo: Editora Claridade, 2004. 


\section{Obras consultadas}

CUENCA, M. C.: Ocio humanista, dimensiones y manifestaciones actuales del ocio. Documentos de Estudios de Ocio, Bilbao/Espanha, num.16. Instituto de Estúdios de Ócio/Universidad de Deusto, 2003.

CUENCA, M. C. e MARTINS. J. C.: Ócio para viver no século XXI. Fortaleza-CE: As Musas. 2008.

DE MASI, D.: O ócio criativo. Rio de Janeiro: Sextante, 2000.

PINHEIRO, K. F.: Corpo do Lazer: reflexões a partir da vida lesada na hipermodernidade. Tese de Doutorado do Programa de Pós-Graduação em Psicologia Social da Universidade do Estado do Rio de Janeiro. UERJ. Rio de Janeiro/RJ. 2010.

REQUIXA, R. As dimensões do lazer. Caderno de Lazer SESC, São Paulo, doc. 1, jul. 1976.

RHODEN, I.: Experiencias personales de ocio: desarrollo de una herramienta para identificación de sus cualidades subjetivas. Bilbao, España: Universidad de Deusto, 2004. 
